\title{
Successful Treatment of a Child with Ruptured Arteriovenous Malformation Using Onyx Embolization: A Case Report
}

\author{
Seidu A. Richard ${ }^{1,2,3}$, Saurav S. Shrestha4, Changwei Zhang, ${ }^{1,4}$, Wei Fu', \\ Ting Wang ${ }^{1,4}$, Wu Cong ${ }^{1,4}$, Xiaodong Xie ${ }^{1,4^{*}}$ \\ ${ }^{1}$ Department of Neurosurgery, West China Hospital, Sichuan University, Chengdu, China \\ ${ }^{2}$ Department of Immunology, Jiangsu University, Zhenjiang, China \\ ${ }^{3}$ Department of Surgery, Volta Regional Hospital, Ghana, West Africa \\ ${ }^{4}$ Department of Neuroradiology Intervention, West China Hospital, Sichuan University, Chengdu, China \\ Email: *gbepoo@gmail.com
}

How to cite this paper: Richard, S.A., Shrestha, S.S., Zhang, C.W., Fu, W., Wang, T., Cong, W. and Xie, X.D. (2017) Successful Treatment of a Child with Ruptured Arteriovenous Malformation Using Onyx Embolization: A Case Report. Open Journal of Modern Neurosurgery, 7, 153-163. https://doi.org/10.4236/ojmn.2017.74016

Received: September 18, 2017

Accepted: October 21, 2017

Published: October 24, 2017

Copyright ( 2017 by authors and Scientific Research Publishing Inc. This work is licensed under the Creative Commons Attribution International License (CC BY 4.0).

http://creativecommons.org/licenses/by/4.0/

\begin{abstract}
Introduction: Arteriovenous Malformations (AVMs) arising deep in the basal ganglia and thalamus encompass a very small fraction of total cerebral AVMs and are rarely encountered in neurosurgery. The rate of rupture of these AVMs is very uncommon making our case more thought-provoking. Case presentation: We present a case of 8-year-old boy with 3 days' history of an intermittent headache with nausea and vomiting. Computer tomographic angiography (CTA) confirmed right basal ganglia and dorsal thalamic hematoma with numerous tortuous blood vessels around the hematoma. Conclusion: We successfully treated this child with ruptured deep seated cerebral AVMs using Onyx embolization with no further neurological deficits.
\end{abstract}

\section{Keywords}

AVM, Onyx Embolization, Basal Ganglia, Thalamus, Hematoma

\section{Introduction}

Arteriovenous Malformations (AVMs) refers to anomalous proliferation or collection of dilated arteries and veins within the brain parenchyma with an anomalous superseding capillary bed, instigating shunting [1] [2] [3]. The occurrences of cerebral AVMs are uncommon in pediatric age group, although they are believed to be congenital [3] [4]. In children, AVMs can manifest as spontaneous hemorrhage resulting in hydrocephalus, non-specific headaches, epilepsy 
or focal neurological deficit [5]. Management of cerebral AVMs usually encompasses multiplicities of treatment modalities such as embolization, surgical removal radio surgery and conservative. Efficient treatment usually focuses on lessening the possibilities of bleeding/rebleeding [6] [7]. Therefore, complete or proximately complete obliteration of the feeding vessels as well as vascular nidus is required. Coil embolization of the AVM followed by surgical resection or radio surgery was the ultimate treatment modalities although complete obliteration of the nidus via embolization was not possible in most cases [3] [6] [7] [8] [9] [10]. Other embolic agents like N-butyl cyanoacrylate (n-BCA) has been used before but with a success rate of 10\% [6] [8] [11].

Currently, a liquid embolic agent called Onyx (eV3, Irvine, California) is the most preferred agent. It is made up of ethylene-vinyl alcohol dissolved in dimethyl sulfoxide (DMSO). It is able to penetrate deeper into the nidus because of its nonadhesive nature as well as slow solidification rate with longer polymerization time. These features allow for a more lengthy and meticulous injection [10] [12] [13] [14] [15] [16]. We present a case of rupture AVM in a child which we successively managed with Onyx embolization.

\section{Case Report}

An 8-year-old boy presented with 3 days' history of an intermittent headache with nausea and vomiting. He was apparently well until the above complaints started prior to presentation at a local hospital. His parents deny any history of loss of consciousness, seizures, incontinence, chest pain or any respiratory distress. His headaches were relieved after vomiting and aggravates mostly in the mornings. He was put on analgesia with no improvement of his condition. His immunization is completed according to his age. Past medical history was unremarkable. Computed Tomography (CT-Scan) done at the local hospital suggest hypothalamic and dorsal thalamic hemorrhage with cerebral AVMs (Figure 1(a) and Figure 1(b)). The patient was referred to our center for further evaluation and treatment. On examination, we saw a young boy who was not acutely ill. Systemic examination revealed no abnormalities. Neurological examination revealed normal cranial nerves. The muscle bulk on the limbs as well power was normal. Routine laboratory and auxiliary investigation (CXR, ECG etc.) were all normal.

Computer tomographic angiography (CTA) confirmed right basal ganglia and dorsal thalamic hematoma with numerous tortuous blood vessels around the hematoma (Figures 2(a)-(d)). The blood vessels supplying the right side of the brain especially internal veins and large cerebral veins are thick, considered as AVMs while the right side of anterior cerebral artery (A1) segment and left posterior cerebral artery (P1) segment are slightly thinner. Digital subtracting angiography (DSA) also indicated right basal ganglia and dorsal thalamus cerebral hemorrhage with thick and numerous tortuous blood vessels measuring about $2.7 \times 1.4 \times 1.5 \mathrm{~cm}$ in diameter with hematoma in right ventricle (Figure 3 (a) and Figure $3(\mathrm{~b})$ ). We made a diagnosis of right basal ganglia and dorsal 


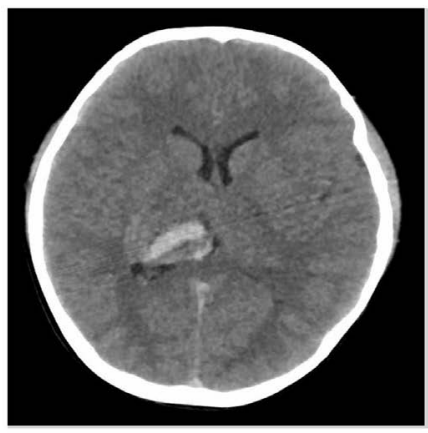

(a)

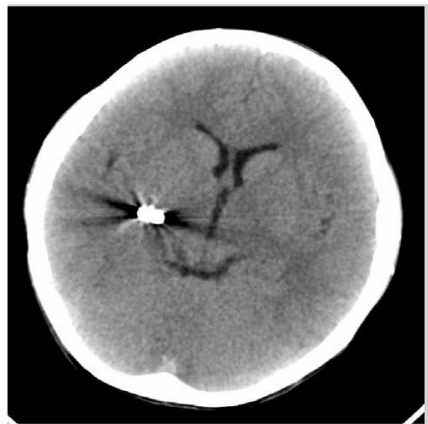

(c)

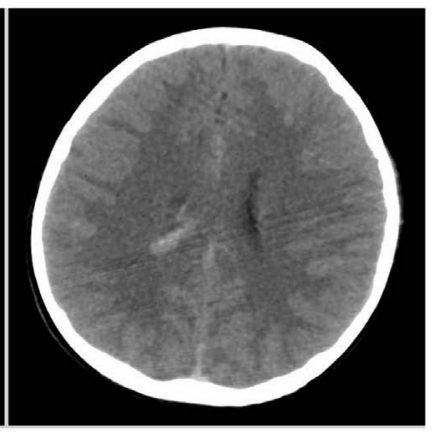

(b)

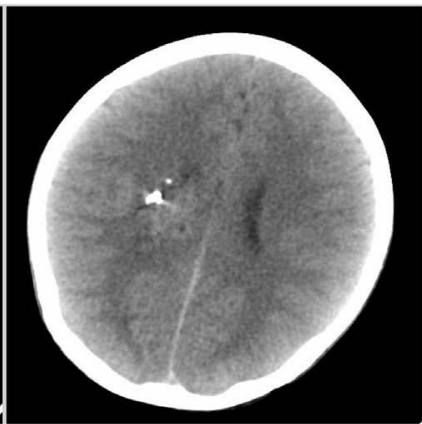

(d)

Figure 1. (a) \& (b) are preoperative CT-Scan images indication hematoma while (c) \& (d) are postoperative CT-Scan images showing the resolution of the hematoma after Onyx embolization.

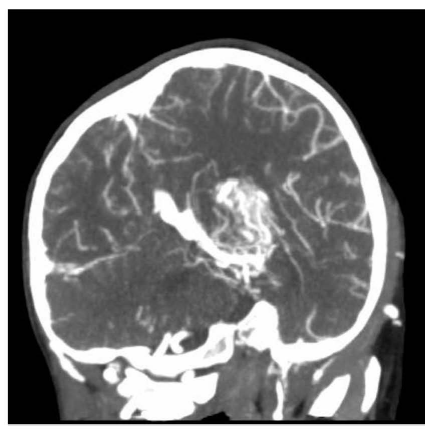

(a)

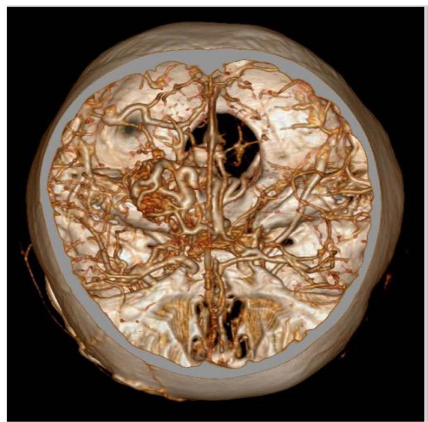

(c)

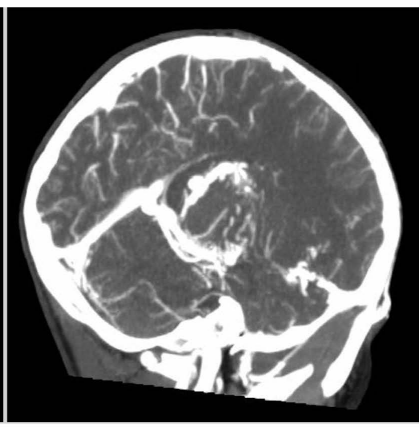

(b)

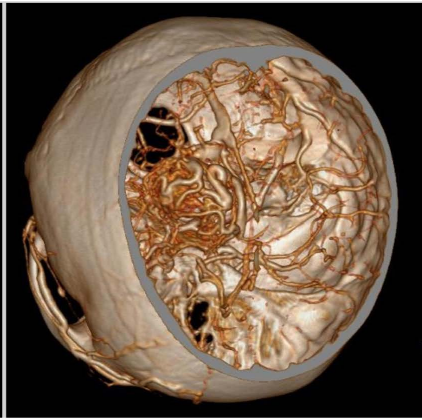

(d)

Figure 2. (a)-(d) are computer tomographic angiography (CTA) confirmed right basal ganglia and dorsal thalamus hematoma with numerous tortuous blood vessels around the hematoma. 


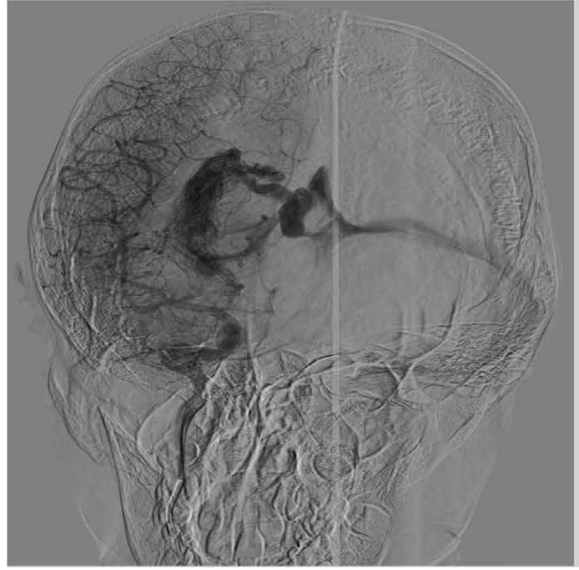

(a)

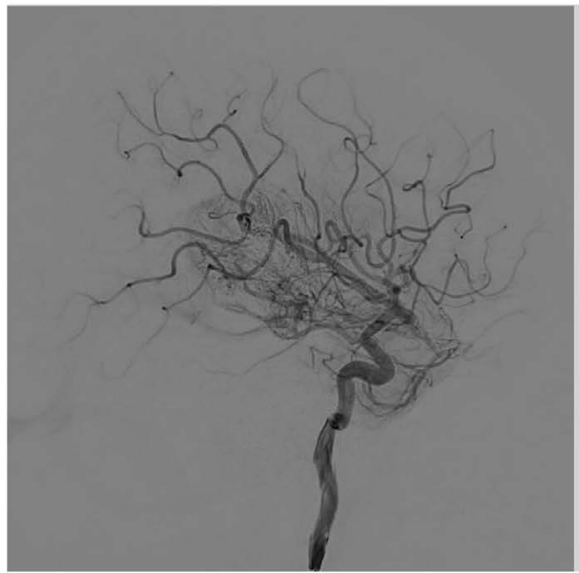

(c)

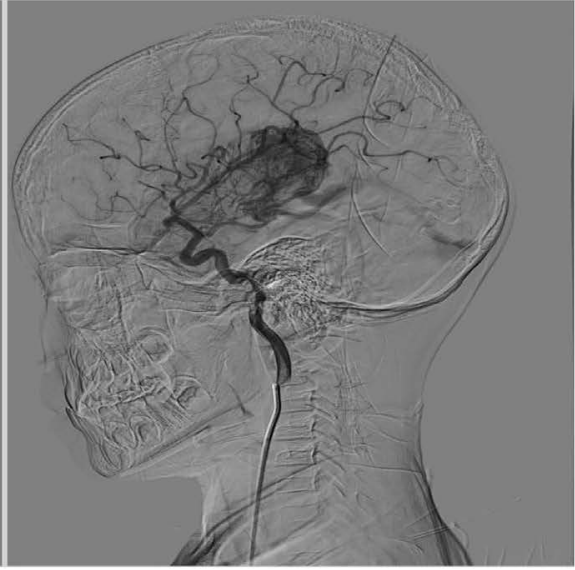

(b)

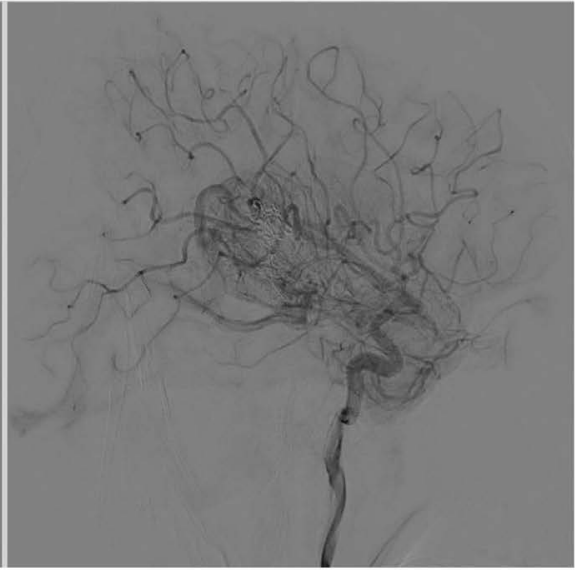

(d)

Figure 3. (a) \& (b) are preoperative DSA images show the AVM while (c) \& (d) are postoperative DSA images showing total occlusion of the AVM with onyx embolization agent.

thalamic AVM. His parents were taken through a series of education and counseling and endovascular embolization treatment scheduled for the next day.

Patient was put into a supine position. Under general anesthesia, $6^{\text {th }} \mathrm{F}$ sheath was placed into the right femoral artery. Cerebral angiography done intraoperatively revealed that the right posterior choroidal artery and posterior arterial branch of the right anterior cerebral artery were draining straight into the sinus. With a continuous pressurized drip of normal saline, the catheter and micro-guide wire was guided into the right internal carotid artery and advanced into the right choroidal artery to reach the AVM and fistula. The micro-guide wire was removed and Onyx embolization agent gradually injected into the $A V M$. Intraoperative angiography done immediately after the procedure revealed successful obliteration of the AVM (Figure 3(c) and Figure 3(d)). Postoperative CT-Scan done two [2] days after the procedure revealed near total reduction in the hematoma size (Figure 1(c) and Figure 1(d)). The patient recovered very quickly and was discharged home 2 -days after the treatment. Outpa- 
tient department visits were scheduled every 3-month. Two years' follow-up revealed no recurrence of his disease.

\section{Discussion}

AVMs arising deep in the basal ganglia and thalamus encompass a very small fraction of total cerebral AVMs. They are rarely seen in typical clinical setting. Studies have established that AVMs in the basal ganglia and thalamus forms about 4.3\% - 11\% of all AVM cases [7] [17] [18]. Fleetwood et al observed an incident rate of about $54.2 \%$ [7]. On the other hand, pediatric AVMs constitutes about $3 \%$ of all AVMs which mean that in the pediatric age group, AVM are not as frequent compare to their adult counterparts [3] [19] [20] [21]. Therefore, our case is very unusual. The etiology of AVMs is still a matter of debate although their angioarchitectural physiognomies and occurrence in all age groups suggest that AVMs possibly have embryonic origin. Notwithstanding this, a sizable number of AVMs don't appear to have hereditary source, though sporadic incidents of familial manifestation have been seen in literature [2] [22]. Occasionally, spontaneously disappearances of AVMs have been reported in literature as well as recurrence after total angiographic obliteration [2] [23] [24].

Studies have indicated that AVMs trigger about $2 \%$ of all strokes and $4 \%$ of hemorrhagic types [2] [25]. Our patient presents with hemorrhagic stroke as result of the reputed AVM. The younger age group is more prone to stroke as compare to their adult counterpart's. AVMs causes one-third of hemorrhagic strokes in children or young adults [2]. Our case is also falls within the pediatric age group. Hemorrhage arising from AVM is mostly less life threatening as compare to the rupture of an intracranial aneurysm or spontaneous hypertensive intracranial hemorrhage, although AVM rupture with accompanying intraparenchymatous hemorrhage frequently leads to substantial neurologic disability. The mortality rate and risk of lifelong morbidity as a result of ruptured AVM differ extensively in various studies, ranges from $5 \%-25 \%$ and $10 \%-40 \%$, correspondingly [2] [26]. Numerous anatomic factors have been implicated in hemorrhagic manifestation of AVMs. Neutral risk factors for hemorrhagic include small size, deep venous drainage, indefinite or nonborder zone (watershed) as well as infratentorial locations, accompanying aneurysms, hypertension, small number of draining veins, venous ectasias, and high feeding artery pressure [2] [27] [28]. Symptomatic epilepsy, which is seen in about $18 \%-35 \%$ of cases is the second most common manifestation of AVMs [2] [26] [28]. Our case did not presented with epilepsy. Anatomic AVM features linked to epileptic manifestations includes large size, cortical location of the nidus or the feeders, and site of the AVM with reference to the middle cerebral artery [2] [29] [30].

The radiological characteristics of a nidus variety of cerebral AVM are consistent with its definition [31]. The diagnostic principles of AVM comprise 1) the existence of a nidus embedded within the brain parenchyma, recognized by both cross-sectional imaging like CT and MRI or conservative angiography; and 2) 
early venous drainage, which is preeminently observed on dynamic studies with typical pointers being conservative catheter angiography. The Precise elucidation of early venous drainage can be determined only if the veins are observed in the "arterial" phase, which is usually recognized on typical magnetic resonance angiography (MRA) or CTA if the shunt volume and draining veins are sizable enough [31]. Furthermore, radiological techniques like dynamic MRA and CTA are gradually being used in the recognition of early drainage for tinier AVMs and thus in determining the diagnosis.CTA was very useful in ruling out other hemorrhage sources as the case of bleeding in our patient. Nevertheless, the above-mentioned principles are imperative indistinguishing brain AVMs from other vascular diseases of the brain [31] [32] [33] [34].

Moreover, two subtypes of anomalous webs of vessels can be seen if a nidus exists. The characteristic form is the glomerular or compact kind nidus, which comprises of anomalous vessels without any interposed normal brain tissue. The second kind which is infrequently observed is the supposed diffuse or proliferative kind nidus, in which normal brain parenchyma is interposed throughout the web of vessels [31]. If the above exist, proliferative angiopathy or cerebrofacial arteriovenous metameric syndrome (CAMS) should be key differential diagnosis. These differentials can be differentiated from true brain AVMs on the basis of the lack of early venous drainage which usually occurs in proliferative angiopathy as well as the typical site and interrelation with facial AVMs observed in CAMS [31]. The arterial feeder vessels and venous drainage of a brain AVM will rely on the site of the nidus. It is now very clear that deep and ventricular AVMs usually have feeders arising from the perforator such as lentriculostriate, thalamoperforator branches and choroidal branches such as anterior, medial, and lateral posterior arteries correspondingly, while venous drainage will classically be via the deep venous plexus [31]. On the other hand, AVMs located superficial or cortically have their main arterial supplies from the pial arteries [31].

Besides conservative treatment, there are three other treatment modalities for brain AVMs. These other modalities include; endovascular embolization, surgical removal or radiosurgery. All this option has their own advantages and disadvantages thus, a multimodality treatment is most generally advisable [4] [31] [35]. Furthermore, there are certain radiological and clinical qualities that are essential in deciding the securest and most efficient management option. Although surgical removal offers a fast remedy in appropriate circumstances; the complication rate relies mainly on the Spetzler-Martin grade: The higher or lower the grade, the higher or lower the complication rate respectively. Thus, surgical resection may be advantageous for cases with smaller and cortical-based brain AVMs [31] [36] [37].

Endovascular embolization is a radiological treatment modality that can be used to rapidly eradicate angiographic risk factors. Although there are no tangible contraindications for endovascular treatment, the outcome of treatment rate with embolization alone is about $10 \%-20 \%$ which is comparatively very low 
except in high flow pialarteriovenous fistulas or small lesions [31] [38]. Furthermore, AVM embolization is not just limited to incomplete nidus embolization, although therapeutic embolization as an alternative to radio surgery or surgical resection is achievable in particular cases. The fundamental facts on therapeutic AVM embolization have distinctly been reported in literature. These facts are: 1) the AVM must be small- or medium-sized measuring about $1-3 \mathrm{~cm}$, not situated in brain stem or deep structures, with feeders from a single vascular zone, reachable by microcatheters and permitting reflux of onyx for $2-3 \mathrm{~cm}, 2$ ) the nidusmust be well demarcated, and 3) the location of the proximal segments of the draining vein must be clear to identify venous filling with onyx. Emphatically, all these anatomical characteristics also make n-BCA appropriate as an embolization agent too [12] [39] [40].

On the other hand, catheter entrapment and angiotoxicity are the particular drawbacks to the use of Onyx embolization in brain AVMs [6]. Furthermore, the reflux of Onyx during the procedure acts as a double-edged sword. Nevertheless, accurate reflux aids in the incessant penetration of Onyx into the nidus to attain acceptable embolization compared with n-BCA. Conventionally, inappropriate reflux usually leads to hitches in removing the microcatheter, which may lead to hemorrhagic complications or catheter entrapment [6]. Xu et al. are of the view that the tortuosity of the feeding artery, the length of the Onyx reflux and the injection time are the key triggers of catheter entrapment. They explain further that Onyx is not a good embolic agent for apparently small tortuous feeding arteries [6]. If Onyx has to be used in cases of small tortuous feeding arteries, the use of microcatheter with detachable tips may aid in decreasing peculiar risks accompanying nondetachable microcatheters [6] [41]. Onyx embolization has also been linked to anigotoxicity with vasospasm or angionecrosis because of its action potential-reducing properties in DMSO [6] [13]. Another most efficient treatment option for deep seated brain AVMs is radio surgery although it may not be appropriate for the treatment of AVMs with angiographic risk factors because of imminent hemorrhage [31]. Furthermore, AVMs with a volume greater than $12 \mathrm{~mL}$ are linked to lower treatment rates as well as higher complication rates. Nevertheless, due to the radiation consequences, it is advisable to use radio surgery treatment options with caution in children [4] [31] [42]. Conservative treatment is normally used when the risk posed by the three [3] treatment modalities above are too high, like in large and deep seated AVMs or in asymptomatic cases in whom imminent hemorrhage is very unlikely [31]. The prognosis of pediatric AVM is usually good if well managed however, re-rupture frequency is projected to be 2 - $4 \%$ with a death rate up to $25 \%$ per every incidence of re-rupture; this risk is greater within 5 years after identification of the AVM [3] [19].

\section{Conclusion}

We successfully treated this child with ruptured deep seated cerebral AVMs us- 
ing Onyx embolization with no further neurological deficits. The first line treatment for our pediatric patient was certainly embolization therapy because of the location of the AVM. Furthermore, surgical removal will be very difficult and radiotherapy did not seem appropriate because of the risks factors associated with radiation in this age group. Two years' follow-up also revealed no recurrence of his disease meaning our treatment has been very effective so far.

\section{Consent for Publication}

The patient and his relatives were dually informed about our intention to publish his case and he/they fully concerted to the use of his documents. The hospital also concerted to the use of this information for publication.

\section{Authors' Contributions}

SAR conceived the project and designed the study. FW, SSS, WT collected patient's data. CWZ, CW and XX provided technical assistance in the study. SAR analyzed the data, prepared the illustrations and wrote the paper. SSS, FW and WT contributed equally to the manuscript. All authors approved the paper for the submission.

\section{Competing Interests}

All the authors have no competing interest to disclose.

\section{References}

[1] Geibprasert, S., Pereira, V., Krings, T., Jiarakongmun, P., Lasjaunias, P. and Pongpech, S. (2009) Hydrocephalus in Unruptured Brain Arteriovenous Malformations: Pathomechanical Considerations, Therapeutic Implications, and Clinical Course. Journal of Neurosurgery, 110, 500-507. https://doi.org/10.3171/2008.7.JNS0815

[2] Laakso, A. and Hernesniemi, J. (2012) Arteriovenous Malformations: Epidemiology and Clinical Presentation. Neurosurgery Clinics of North America, 23, 1-6.

https://doi.org/10.1016/j.nec.2011.09.012

[3] El-Ghanem, M., Kass-Hout, T., Kass-Hout, O., Alderazi, Y.J., Amuluru, K., Al-Mufti, F., et al. (2016) Arteriovenous Malformations in the Pediatric Population: Review of the Existing Literature. Interventional Neurology, 5, 218-225. https://doi.org/10.1159/000447605

[4] Söderman, M., Andersson, T., Karlsson, B., Wallace, M.C. and Edner, G. (2003) Management of Patients with Brain Arteriovenous Malformations. European Journal of Radiology, 46, 195-205. https://doi.org/10.1016/S0720-048X(03)00091-3

[5] Ventureyra, E. and Herder, S. (1987) Arteriovenous Malformations of the Brain in Children. Child's Nervous System, 3, 12-18. https://doi.org/10.1007/BF00707187

[6] Xu, F., Ni, W., Liao, Y., Gu, Y., Xu, B., Leng, B., et al. (2011) Onyx Embolization for the Treatment of Brain Arteriovenous Malformations. Acta Neurochirurgica, 153, 869-878. https://doi.org/10.1007/s00701-010-0848-6

[7] Fleetwood, I.G., Marcellus, M.L., Levy, R.P., Marks, M.P. and Steinberg, G.K. (2003) Deep Arteriovenous Malformations of the Basal Ganglia and Thalamus: Natural History. Journal of Neurosurgery, 98, 747-750. 
https://doi.org/10.3171/jns.2003.98.4.0747

[8] Gobin, Y.P., Laurent, A., Merienne, L., Schlienger, M., Aymard, A., Houdart, E., et al. (1996) Treatment of Brain Arteriovenous Malformations by Embolization and Radiosurgery. Journal of Neurosurgery, 85, 19-28. https://doi.org/10.3171/jns.1996.85.1.0019

[9] Viñuela, F., Dion, J.E., Duckwiler, G., Martin, N.A., Lylyk, P., Fox, A., et al. (1991) Combined Endovascular Embolization and Surgery in the Management of Cerebral Arteriovenous Malformations: Experience with 101 Cases. Journal of Neurosurgery, 75, 856-864. https://doi.org/10.3171/jns.1991.75.6.0856

[10] Nerva, J.D., Barber, J., Levitt, M.R., Rockhill, J.K., Hallam, D.K., Ghodke, B.V., et al. (2017) Onyx Embolization Prior to Stereotactic Radiosurgery for Brain Arteriovenous Malformations: A Single-Center Treatment Algorithm. Journal of Neuro Interventional Surgery, 2017, Article ID: 013084.

[11] Meisel, H., Mansmann, U., Alvarez, H., Rodesch, G., Brock, M. and Lasjaunias, P. (2002) Effect of Partial Targeted N-butyl-cyano-acrylate Embolization in Brain AVM. Acta Neurochirurgica, 144, 879-888. https://doi.org/10.1007/s00701-002-0978-6

[12] Saatci, I., Geyik, S., Yavuz, K. and Cekirge, H.S. (2011) Endovascular Treatment of Brain Arteriovenous Malformations with Prolonged Intranidal Onyx Injection Technique: Long-Term Results in 350 Consecutive Patients with Completed Endovascular Treatment Course. Journal of Neurosurgery, 115, 78-88. https://doi.org/10.3171/2011.2.JNS09830

[13] Jahan, R., Murayama, Y., Pierre Gobin, Y., Duckwiler, G.R., Vinters, H.V. and Viñuela, F. (2001) Embolization of Arteriovenous Malformations with Onyx: Clinicopathological Experience in 23 Patients. Neurosurgery, 48, 984-997.

[14] Lagares, A., Lobato, R.D., Ricoy, J.R. and Campollo, J. (2002) Embolization of Arteriovenous Malformations with Onyx: Clinicopathological Experience in 23 Patients. Neurosurgery, 51, 1525-1526. https://doi.org/10.1227/01.NEU.0000309133.44903.12

[15] Yamashita, K., Taki, W., Iwata, H., Nakahara, I., Nishi, S., Sadato, A., et al. (1994) Characteristics of Ethylene Vinyl Alcohol Copolymer (EVAL) Mixtures. American Journal of Neuroradiology, 15, 1103-1105.

[16] Vollherbst, D.F., Sommer, C.M., Ulfert, C., Pfaff, J., Bendszus, M. and Möhlenbruch, M.A. (2017) Liquid Embolic Agents for Endovascular Embolization: Evaluation of an Established (Onyx) and a Novel (PHIL) Embolic Agent in an in Vitro AVM Model. American Journal of Neuroradiology. https://doi.org/10.3174/ajnr.A5203

[17] Deruty, R., Pelissou-Guyotat, I., Mottolese, C., Bascoulergue, Y. and Amat, D. (1993) The Combined Management of Cerebral Arteriovenous Malformations Experience with 100 Cases and Review of the Literature. Acta Neurochirurgica, 123, 101-112. https://doi.org/10.1007/BF01401864

[18] Malik, G.M., Umansky, F., Patel, S. and Ausman, J.I. (1988) Microsurgical Removal of Arteriovenous Malformations of the Basal Ganglia. Neurosurgery, 23, 209-217. https://doi.org/10.1227/00006123-198808000-00014

[19] Di Rocco, C., Tamburrini, G. and Rollo, M. (2000) Cerebral Arteriovenous Malformations in Children. Acta Neurochirurgica, 142, 145-158.

https://doi.org/10.1007/s007010050017

[20] Humphreys, R.P., Hoffman, H.J., Drake, J.M. and Rutka, J.T. (1996) Choices in the 1990s for the Management of Pediatric Cerebral Arteriovenous Malformations. Pediatric Neurosurgery, 25, 277-285. https://doi.org/10.1159/000121140 
[21] Millar, C., Bissonnette, B. and Humphreys, R. (1994) Cerebral Arteriovenous Malformations in Children. Canadian Journal of Anesthesia, 41, 321-331. https://doi.org/10.1007/BF03009913

[22] Van Beijnum, J., Van der Worp, H., Schippers, H., Van Nieuwenhuizen, O., Kappelle, L., Rinkel, G., et al. (2007) Familial Occurrence of Brain Arteriovenous Malformations: A Systematic Review. Journal of Neurology, Neurosurgery \& Psychiatry, 78, 1213-1217. https://doi.org/10.1136/jnnp.2006.112227

[23] Lee, S., Vilela, P., Willinsky, R. and TerBrugge, K. (2002) Spontaneous Regression of Cerebral Arteriovenous Malformations: Clinical and Angiographic Analysis with Review of the Literature. Neuroradiology, 44, 11-16. https://doi.org/10.1007/s002340100702

[24] Buis, D.R., van den Berg, R., Lycklama, G., van der Worp, H.B., Dirven, C.M. and Vandertop, W.P. (2004) Spontaneous Regression of Brain Arteriovenous Malformations. Journal of Neurology, 251, 1375-1382. https://doi.org/10.1007/s00415-004-0548-3

[25] Al-Shahi, R. and Warlow, C. (2001) A Systematic Review of the Frequency and Prognosis of Arteriovenous Malformations of the Brain in Adults. Brain, 124, 1900-1926. https://doi.org/10.1093/brain/124.10.1900

[26] Ondra, S.L., Troupp, H., George, E.D. and Schwab, K. (1990) The Natural History of Symptomatic Arteriovenous Malformations of the Brain: A 24-Year Follow-Up Assessment. Journal of Neurosurgery, 73, 387-391. https://doi.org/10.3171/jns.1990.73.3.0387

[27] David, J.L., Todd, M.L., Robert, W.H., Eugene, S.F. and Eric, C.F. (1998) Hypertension, Small Size, and Deep Venous Drainage Are Associated with Risk of Hemorrhagic Presentation of Cerebral Arteriovenous Malformations. Neurosurgery, 42, 481-489. https://doi.org/10.1097/00006123-199803000-00008

[28] Stapf, C., Mast, H., Sciacca, R., Choi, J., Khaw, A., Connolly, E., et al. (2006) Predictors of Hemorrhage in Patients with Untreated Brain Arteriovenous Malformation. Neurology, 66, 1350-1355. https://doi.org/10.1212/01.wnl.0000210524.68507.87

[29] Crawford, P., West, C. and Shaw, M. (1986) Cerebral Arteriovenous Malformations and Epilepsy: Factors in the Development of Epilepsy. Epilepsia, 27, 270-275. https://doi.org/10.1111/j.1528-1157.1986.tb03539.x

[30] Turjman, F., Massoud, T.F., Sayre, J.W., Vi, F., Guglielmi, G. and Duckwiler, G. (1995) Epilepsy Associated with Cerebral Arteriovenous Malformations: A Multivariate Analysis of Angioarchitectural Characteristics. American Journal of Neuroradiology, 16, 345-350.

[31] Geibprasert, S., Pongpech, S., Jiarakongmun, P., Shroff, M.M., Armstrong, D.C. and Krings, T. (2010) Radiologic Assessment of Brain Arteriovenous Malformations: What Clinicians Need to Know. Radiographics, 30, 483-501. https://doi.org/10.1148/rg.302095728

[32] Griffiths, P.D., Hoggard, N., Warren, D.J., Wilkinson, I.D., Anderson, B. and Romanowski, C.A. (2000) Brain Arteriovenous Malformations: Assessment with Dynamic MR Digital Subtraction Angiography. American Journal of Neuroradiology, 21, 1892-1899.

[33] Krings, T. and Hans, F. (2004) New Developments in MRA: Time-Resolved MRA. Neuroradiology, 46, s214-s224. https://doi.org/10.1007/s00234-004-1332-x

[34] Reinacher, P., Reinges, M.H., Simon, V.A., Hans, F.J. and Krings, T. (2007) Dynamic 3-D Contrast-Enhanced Angiography of Cerebral Tumours and Vascular Malformations. European Radiology Supplements, 17, 52-62. 
https://doi.org/10.1007/s10406-007-0229-2

[35] Richling, B., Killer, M., Al-Schameri, A.R., Ritter, L., Agic, R. and Krenn, M. (2006) Therapy of Brain Arteriovenous Malformations: Multimodality Treatment from a Balanced Standpoint. Neurosurgery, 59, S3-148-S3-57.

[36] Hamilton, M.G. and Spetzler, R.F. (1994) The Prospective Application of a Grading System for Arteriovenous Malformations. Neurosurgery, 34, 2-7.

[37] Lawton, M.T. (2003) Spetzler-Martin Grade III Arteriovenous Malformations: Surgical Results and a Modification of the Grading Scale. Neurosurgery, 52, 740-749. https://doi.org/10.1227/01.NEU.0000053220.02268.9C

[38] Andreou, A., Ioannidis, I. and Nasis, N. (2008) Transarterial Balloon-Assisted Glue Embolization of High-Flow Arteriovenous Fistulas. Neuroradiology, 50, 267-272. https://doi.org/10.1007/s00234-007-0322-1

[39] Van Rooij, W., Jacobs, S., Sluzewski, M., Van der Pol, B., Beute, G. and Sprengers, M. (2012) Curative Embolization of Brain Arteriovenous Malformations with Onyx: Patient Selection, Embolization Technique, and Results. American Journal of Neuroradiology, 33, 1299-1304. https://doi.org/10.3174/ajnr.A2947

[40] Natarajan, S.K., Born, D., Ghodke, B., Britz, G.W. and Sekhar, L.N. (2009) Histopathological Changes in Brain Arteriovenous Malformations after Embolization Using Onyx or N-Butyl Cyanoacrylate. Journal of Neurosurgery, 111, 105-113. https://doi.org/10.3171/2008.12.JNS08441

[41] Maimon, S., Strauss, I., Frolov, V., Margalit, N. and Ram, Z. (2010) Brain Arteriovenous Malformation Treatment Using a Combination of Onyx and a New Detachable Tip Microcatheter, SONIC: Short-Term Results. American Journal of Neuroradiology, 31, 947-954. https://doi.org/10.3174/ajnr.A1959

[42] Pollock, B. (1999) Stereotactic Radiosurgery for Arteriovenous Malformations. Neurosurgery Clinics of North America, 10, 281-290. 